\title{
Diethylamine functionalized polyethylene glycol as a novel and efficient catalyst for Knoevenagel condensation
}

\author{
WEN YE, HONG JIANG* and XIAN-CAO YANG \\ College of Science, Huazhong Agricultural University, Wuhan, Hubei 430070, China \\ e-mail: jianghong0066@126.com
}

MS received 8 July 2010; revised 20 January 2011; accepted 28 February 2011

\begin{abstract}
The Knoevenagel condensation of aromatic aldehydes with active methylene is an efficient reaction for carbon-carbon double bond formation. A rapid, efficient, and ecofriendly protocol for the Knoevenagel condensation of active methylene compounds with aldehydes has been developed with diethylamine functionalized polyethylene glycol-600 (PEG-600) as catalyst with good to excellent yields at room temperature without solvent.
\end{abstract}

Keywords. Knoevenagel condensation; modified polyethylene glycol; room temperature; solvent-free.

\section{Introduction}

The Knoevenagel condensation between aldehydes and active methylenes is an important reactions in organic synthesis in forming carbon-carbon double bond, and the products have E-isomer dominantly. Knoevenagel condensation has been receiving considerable attention, due to its broad spectrum of uses including cosmetic, perfume, pharmaceutical, agrochemicals, and pharmaceuticals applications. ${ }^{1,2}$ In last ten years, lots of methods to achieve Knoevenagel condensation are known, For example, some novel heating methods such as microwave irradiation, ${ }^{3-6}$ ultrasonic heating ${ }^{7,8}$ had been applied in Knoevenagel condensation; in the mean time, accumulating efforts have been made to explore novel catalysts for Knoevenagel reaction. ${ }^{9-21}$ However some of these methods suffer from some drawbacks such as long reaction time, the use of harmful catalyst, lots of solvent, and energy expenses.

In this report, we use modified PEG with tertiary amine moiety as catalyst, which is synthesized as in scheme 1. Base has been extensively investigated in catalysing Knoevenagel reaction. ${ }^{22}$ As a kind of base, diethylamine functionalized Polyethylene glycol (PEG) makes the Knoevenagel condensation at room temperature with good to excellent yields (scheme 2). The catalyst can be easily recycled and reused without noticeably decreasing in productivity.

*For correspondence

\section{Experimental}

\subsection{Synthesis of the catalyst}

2.1a Reactants and reagents: PEG600, toluene, pyridine, thionyl chloride, sodium carbonate, absolute ethanol, diethylamine were purchased from China Chemical Reagent Company.

$2.1 \mathrm{~b}$ The synthesis of dichloro substituted PEG600: ${ }^{23,24}$ PEG600 (15 g, $0.025 \mathrm{~mol}$ ) and pyridine $(5 \mathrm{~mL}, 0.0625 \mathrm{~mol})$ was dissolved in toluene $(20 \mathrm{~mL})$, stirred at $87^{\circ} \mathrm{C}$, thionyl chloride $(5 \mathrm{~mL}, 0.0625 \mathrm{~mol})$ was added slowly, and the resultant reaction mixture was stirred for $15 \mathrm{~h}$ at $87^{\circ} \mathrm{C}$. Then the resulting solid was removed by filtration. After removal of the solvent under reduced pressure a viscous liquid residual was collected as dichloro substituted PEG600 (13.75 g, $91.6 \%)$.

2.1c The synthesis of diethylamine functionalized PEG: Drop the dichloro substituted PEG600 (7.5 g, $0.0125 \mathrm{~mol}$ ) into the mixture of absolute ethanol $(10 \mathrm{~mL})$, diethylamine $(3.1 \mathrm{~mL}, 0.03 \mathrm{~mol})$, sodium carbonate $(1.6 \mathrm{~g}, 0.015 \mathrm{~mol})$, which was stirred at $80{ }^{\circ} \mathrm{C}$ for $20 \mathrm{~h}$. Then the solid produced was filtered. After removal of the solvent under reduced pressure, diethylamine functionalized PEG was collected as a brown viscous liquid $(8.50 \mathrm{~g}, 89.4 \%$, the spectrum is listed below).

2.1d Catalyst ( $\left.E t_{2} N-P E-N E t_{2}\right)$ : brown liquid. ${ }^{1} \mathrm{H}$ NMR $\left(600 \mathrm{MHz}, \mathrm{CDCl}_{3}\right): \delta 3.572(s, 60 \mathrm{H}), 2.514-2.478$ 


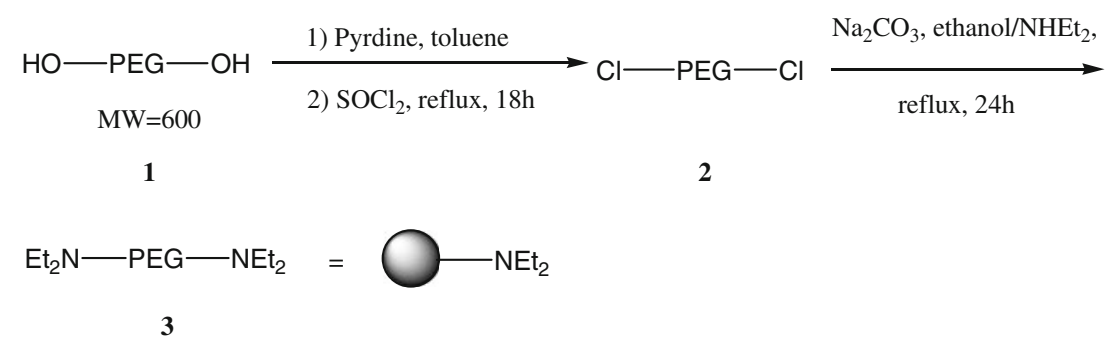

Scheme 1. The synthesis of the catalyst.

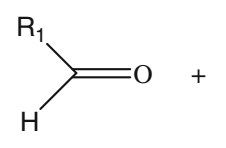

4

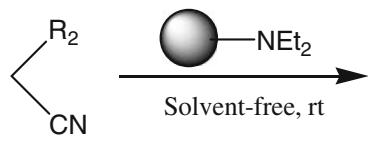

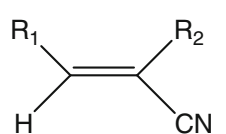

6
Scheme 2. Knoevenagel condensation between aromatic aldehydes and active methylenes.

(q, $J=7.2 \mathrm{~Hz}, 8 \mathrm{H}), 0.965-0.941(\mathrm{t}, J=7.2 \mathrm{~Hz}, 12$ H). IR (KBr): v 2870, 2359, 1456, 1349, $1108 \mathrm{~cm}^{-1}$.

\subsection{General procedure for Knoevenagel reaction}

To a mixture of aldehyde 4 ( $5 \mathrm{mmol}$ ) and active methylene compound $5(5 \mathrm{mmol})$, the modified PEG600 $(10 \mathrm{~mol} \%)$ was added and the resultant mixture was vigorously ground using a mortar and pestle at room temperature for the specified time until TLC showed complete disappearance of the starting material (table 1). Then $5 \mathrm{~mL}$ cool water was added, the reaction mixture was filtered to yield the product $\mathbf{6}$ in excellent yield. After removal of the water from the filtrate by evaporation, the catalyst can be reused in next run.

\section{Results and discussion}

The reaction of various aromatic aldehyde with active methylene (such as ethyl cyanoacetate and malononitrile) was carried out at room temperature without solvent. Rapid reaction rates and high conversions were achieved and the results are presented in table 1, all the products listed below are known compounds.

As we know, the Knoevenagel reaction is generally carried out in the presence of weak bases such as ethylenediamine, piperidine or corresponding ammonium salts, under homogeneous conditions. In our study, the modified PEG600 with tertiary amine moiety has been employed as a novel, mild and efficient catalyst for this condensation. Accordingly, treatment of $p$-chlorobenzaldehyde with malononitrile in the presence of $10 \mathrm{~mol} \%$ of the modified PEG600 at room temperature resulted in the formation of olefin in $99 \%$ yield in one minute. In a similar manner, a wide range of substrates react efficiently with malononitrile under the same reaction conditions to give the corresponding olefins (table 1).

Both electron-rich and electron-deficient aldehydes worked well, giving high yields of products. Electrondeficient aldehydes furnished excellent yields of the corresponding arylidenes in a short reaction time, whereas electron-rich aldehydes resulted in comparatively low yields and required longer reaction times (table 1).

It is noteworthy to mention that the reaction between aldehyde and malononitrile could get higher yield and require shorter reaction time than that between the corresponding aldehyde and ethyl cyanoacetate, in which the reaction time differ greatly $(1-40 \mathrm{~min})$. This can be ascribed to the $\mathrm{C}-\mathrm{H}$ acidity of the active methylene compounds. Cyano functional group has a stronger electron-withdrawing ability than the ester group, so it is easier for malononitrile bearing two cyano groups to generate an anion than ethyl cyanoacetate in the presence of base and hence react much faster with aldehydes.

\subsection{The mechanism of diethylamine-modified PEG600}

To compare the catalytic effect of the diethylaminemodified PEG600, the reaction performances between $p$ chlorobenzaldehyde and malononitrile was also carried out in the presence of PEG600, the dichloro-modified PEG600, respectively (6c, 6d, 6e in table 1), among which the diethylamine-modified PEG600 was found to be the most effective catalyst. PEG600 also demonstrated some catalytic activity, but required much longer reaction time than diethylamine-modified PEG600. However, the reaction does not proceed under similar conditions even after a longer time (approximately $6 \mathrm{~h}$ ) just in the presence of dichloro-modified PEG600. 
Table 1. Diethylamine-modified PEG600 catalysed Knoevenagel condensation.

\begin{tabular}{|c|c|c|c|c|c|c|}
\hline Entry & $\mathrm{R}^{1}$ & $\mathrm{R}^{2}$ & Time (min) & Comp. & Yield $(\%)^{\mathrm{b}}$ & M.p. (L) $\left({ }^{\circ} \mathrm{C}\right)$ \\
\hline 1 & $\mathrm{C}_{6} \mathrm{H}_{5}$ & $\mathrm{CN}$ & 1 & $\mathbf{6 a}$ & 91 & $82-83(82-85)^{19}$ \\
\hline 2 & $2-\mathrm{ClC}_{6} \mathrm{H}_{4}$ & $\mathrm{CN}$ & $<1$ & $\mathbf{6 b}$ & 98 & $94-96(96-97)^{9}$ \\
\hline 3 & $4-\mathrm{ClC}_{6} \mathrm{H}_{4}$ & $\mathrm{CN}$ & 180 & $6 c^{c}$ & 63 & $158-160(164)^{19}$ \\
\hline 4 & $4-\mathrm{ClC}_{6} \mathrm{H}_{4}$ & $\mathrm{CN}$ & 360 & $6 c^{\mathrm{d}}$ & No reaction & \\
\hline 5 & $4-\mathrm{ClC}_{6} \mathrm{H}_{4}$ & $\mathrm{CN}$ & $<1$ & $6 c$ & 99 & \\
\hline 6 & $4-\mathrm{NMe}_{2} \mathrm{C}_{6} \mathrm{H}_{5}$ & $\mathrm{CN}$ & 1 & 6d & 95 & $180-182(179-180)^{17}$ \\
\hline 7 & $4-\mathrm{CH}_{3} \mathrm{OC}_{6} \mathrm{H}_{4}$ & $\mathrm{CN}$ & 1 & $6 e$ & 94 & $115-116(111-115)^{19}$ \\
\hline 8 & $3-\mathrm{NO}_{2} \mathrm{C}_{6} \mathrm{H}_{4}$ & $\mathrm{CN}$ & $<1$ & $6 f$ & 96 & $102-103(104-105)^{9}$ \\
\hline 9 & $4-\mathrm{NO}_{2} \mathrm{C}_{6} \mathrm{H}_{4}$ & $\mathrm{CN}$ & $<1$ & $6 \mathrm{~g}$ & 97 & $159-160(160-161)^{17}$ \\
\hline 10 & 2-Furyl & $\mathrm{CN}$ & 1 & $6 \mathrm{~h}$ & 93 & $66-67(67-68)^{19}$ \\
\hline 11 & $\mathrm{C}_{6} \mathrm{H}_{5}$ & $\mathrm{CO}_{2} \mathrm{Et}$ & 6 & $6 \mathbf{i}$ & 93 & $50-52(49-50)^{6}$ \\
\hline 12 & $2-\mathrm{ClC}_{6} \mathrm{H}_{4}$ & $\mathrm{CO}_{2} \mathrm{Et}$ & 12 & $6 \mathbf{j}$ & 90 & $52-53(53)^{19}$ \\
\hline 13 & $4-\mathrm{ClC}_{6} \mathrm{H}_{4}$ & $\mathrm{CO}_{2} \mathrm{Et}$ & 3 & $6 \mathbf{k}$ & 96 & $87-88(92-94)^{19}$ \\
\hline 14 & $4-\mathrm{NMe}_{2} \mathrm{C}_{6} \mathrm{H}_{5}$ & $\mathrm{CO}_{2} \mathrm{Et}$ & 30 & 61 & 95 & $123-125(124-126)^{19}$ \\
\hline 15 & $4-\mathrm{CH}_{3} \mathrm{OC}_{6} \mathrm{H}_{4}$ & $\mathrm{CO}_{2} \mathrm{Et}$ & 40 & $6 m$ & 90 & $80-82(80-81)^{17}$ \\
\hline 16 & $3-\mathrm{NO}_{2} \mathrm{C}_{6} \mathrm{H}_{4}$ & $\mathrm{CO}_{2} \mathrm{Et}$ & 3 & $6 n$ & 94 & $133-135(134-135)^{9}$ \\
\hline 17 & $4-\mathrm{NO}_{2} \mathrm{C}_{6} \mathrm{H}_{4}$ & $\mathrm{CO}_{2} \mathrm{Et}$ & 2 & 60 & 93 & $166-168(166-167)^{17}$ \\
\hline 18 & 2-Furyl & $\mathrm{CO}_{2} \mathrm{Et}$ & 1 & $6 p$ & 99 & $90-91(89-91)^{19}$ \\
\hline
\end{tabular}

a The reaction was carried out using aldehyde $(5 \mathrm{mmol})$, and active methylene compound $(5 \mathrm{mmol})$, the diethylamine-modified PEG600 (10 mol\%). All the products are known compounds and were identified by comparison of their melting points and spectral data with those reported

$\mathrm{b}$ Isolated yield

${ }^{\mathrm{c}}$ With the PEG

${ }^{\mathrm{d}}$ With the dichloro-modified PEG600

Diethylamine-modified PEG600 acts as a mild Lewis base to induce the reaction. A postulated reaction mechanism is shown in scheme 3 .

The diethylamine-modified PEG600 is watersoluble, so it is easy to separate the products by simple extraction with dichloromethane. After evaporation of the water, the catalyst can be recycled and be reused without obviously decreasing the catalytic activity and the reused times do not affect the selectivity of product.

In addition, the use of diethylamine-modified PEG600 as a catalyst helps to avoid the use of environmentally unfavourable organic solvents as reaction medium since the reaction proceeds smoothly under solvent-free conditions. It is noteworthy that all products $\mathbf{6}$ were easily isolated by simple filtration and no purification was required.

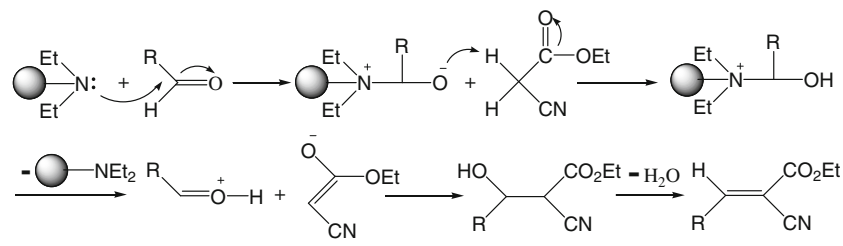

Scheme 3. The postulated mechanism of Knoevenagel condensation.

\section{Conclusion}

In summary, diethylamine-modified PEG600 has been employed for the first time as a novel and efficient catalyst for Knoevenagel reaction under solvent-free conditions. This catalyst is applicable to a wide range of aldehyde substrates. The attractive features of this procedure are the mild reaction conditions, high conversions, easy to prepare the catalyst, clean reaction profiles, solvent-free reaction conditions, operational simplicity and recycle of the catalyst, all of which make it a useful and attractive strategy for Knoevenagel reaction.

\section{Supporting information}

Compounds $\mathbf{6 a - p}$ details are given in supporting information (see www.ias.ac.in/chemsci).

\section{References}

1. Bian Y J, Qing Y, Xiao L W and Li J T 2006 Chinese J. Org. Chem. 261165

2. Chalais S, Laszlo P and Mathy A 1985 Tetrahedron Lett. 264453

3. Villemin D and Martin B 1995 Synth. Commun. 252319 
4. de la Cruz P, Diez-Barra E, Loupy A and Langa F 1996 Tetrahedron Lett. 371113

5. Mitra A K, De A and Karchaudhuri N 1999 Synth. Commun. 292731

6. Yadav J S, Reddy B V S, Basak A K, Visali B, Narsaiah A V and Nagaiah K 2004 Eur. J. Org. Chem. 546

7. Martin-Aranda R M, Ortega-Cantero E, RojasCervantes M L, Vicente-Rodriguez M A and BanaresMunoz M A 2005 J. Chem. Technol. Biot. 80 234

8. Wang X T, Liang B and Wang J X 2007 Chem. Res. Appl. $\mathbf{5}$

9. Sun Q, Shi L X, Ge Z M, Cheng T M and Li R T 2005 Chinese. J. Chem. 23745

10. Bennazha J, Zahouilly M, Boukhari A and Holt E M 2003 J. Mol. Catal. A: Chem. 202247

11. Zahouily M, Bahlaouan B, Solhy A, Ouammou M and Sebti S 2003 React. Kinet. Catal. Lett. 78129

12. Narsaiah A V, Basak A K, Visali B and Nagaiah K 2004 Synth. Commun. 342893

13. Deb M L and Bhuyan P J 2005 Tetrahedron Lett. 466453
14. List B, Doehring A, Fonseca $\mathrm{M} \mathrm{T} \mathrm{H}$, Wobser $\mathrm{K}$, van Thienen $\mathrm{H}$, Torres R R and Galilea P L $2005 A d v$. Synth. Catal. 3471558

15. Tamami B and Fadavi A 2005 Catal. Commun. 6747

16. Bass J D, Solovyov A, Pascall A J and Katz A $2006 J$. Am. Chem. Soc. 1283737

17. Liu Y, Liang J, Liu X, Fan J and Shang Z 2008 Chinese. Chem. Lett. 191043

18. Santamarta F, Verdía P and Tojo E 2008 Catal. Commun. 91779

19. Yue C, Mao A, Wei Y and Li M J 2008 Catal. Commun. 91571

20. Fang D, Fei Z H and Liu Z L 2008 Monatsh. Chem. 139779

21. Ren Y M and Cai C 2007 Catal. Lett. 118134

22. Parida K M, Rath D and Mol J 2009 Catal. A: Chem. 31093

23. Liang X and Li S Z 1996 Ion Exchange and Adsorption 12309

24. Wang X, Li L, Quan Z, Gong H, Ye H and Cao X 2009 Chinese. Chem. Lett. 20651 